\title{
Confirmation of quantitative trait loci affecting fatness in chickens
}

\author{
Danyel G.J. JENNEN ${ }^{\mathrm{a}, \mathrm{b} *}$, Addie L.J. VEREIJKEN ${ }^{\mathrm{c}}$, \\ Henk BovenHUIS ${ }^{\mathrm{a}}$, Richard M.P.A. CROOIJMANS ${ }^{\mathrm{a}}$, \\ Jan J. van der POEL ${ }^{\mathrm{a}}$, Martien A.M. GROENEN ${ }^{\mathrm{a}}$ \\ a Animal Breeding and Genetics Group, Wageningen Institute of Animal Sciences, \\ Wageningen University, Marijkeweg 40, 6709 PG Wageningen, The Netherlands \\ ${ }^{\mathrm{b}}$ Institute of Animal Breeding Science, University Bonn, Endenicher Allee 15, \\ 53113 Bonn, Germany \\ ${ }^{\mathrm{c}}$ Nutreco, Breeding Research Centre, P.O. Box 220, 5830 AE Boxmeer, The Netherlands
}

(Received 8 September 2003; accepted 16 August 2004)

\begin{abstract}
In this report we describe the analysis of an advanced intercross line (AIL) to confirm the quantitative trait locus (QTL) regions found for fatness traits in a previous study. QTL analysis was performed on chromosomes $1,3,4,15,18$, and 27 . The AIL was created by random intercrossing in each generation from generation $2\left(\mathrm{G}_{2}\right)$ onwards until generation $9\left(\mathrm{G}_{9}\right)$ was reached. QTL for abdominal fat weight (AFW) and/or percentage abdominal fat (AF\%) on chromosomes 1, 3 and 27 were confirmed in the $\mathrm{G}_{9}$ population. In addition, evidence for QTL for body weight at the age of 5 (BW5) and 7 (BW7) weeks and for the percentage of intramuscular fat (IF\%) were found on chromosomes 1, 3, 15, and 27. Significant evidence for QTL was detected on chromosome 1 for BW5 and BW7. Suggestive evidence was found on chromosome 1 for $\mathrm{AFW}, \mathrm{AF} \%$ and $\mathrm{IF} \%$, on chromosome 15 for BW5, and on chromosome 27 for $\mathrm{AF} \%$ and IF\%. Furthermore, evidence on the chromosome-wise level was found on chromosome 3 for AFW, AF\%, and BW7 and on chromosome 27 for BW5. For chromosomes 4 and 18, test statistics did not exceed the significance threshold.
\end{abstract}

quantitative trait loci / advanced intercross line / chicken / fatness traits

\section{INTRODUCTION}

Fat deposition is an important trait in the chicken, which has been examined in several studies for the identification and localization of quantitative trait loci (QTL) (e.g. Tatsuda and Fujinaka [23]; Ikeobi et al. [14]; McElroy et al. [19]; Pitel et al. [20]). We previously identified QTL affecting fatness in a cross

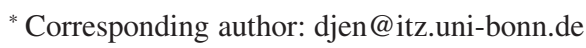


between two genetically different outcross broiler dam lines originating from the White Plymouth Rock breed [16]. This resulted in a genomewise significant QTL for the percentage of abdominal fat at the age of 10 weeks on chicken chromosome 1. This QTL explained about $18 \%$ of the total genetic variance. Furthermore, suggestive QTL for fatness traits were found on chromosomes 1, $2,3,4,7,11,13,15,18$ and 27. Confirmation of these QTL is an essential step before attempts are made towards the fine mapping of the QTL and the identification of genes underlying the traits of interest.

Confirmation of the presence and location of the QTL of interest can be achieved by comparing the results from different QTL studies. In the comparison of two granddaughter designs Bennewitz et al. [2] confirmed QTL affecting milk yield in cattle. In the study of two distinct layer $\times$ layer crossess, Siwek et al. [22] validated the presence of a QTL for the primary antibody response to keyhole lympet hemocyanin on chromosome 14 in both populations. Confirmation of QTL within a commercial broiler line was achieved by De Koning et al. [8]. In this study QTL for body weight and residual feed intake on chicken chromosome 4 were confirmed from results from other QTL studies reported in the literature. Some, but not all of the fatness QTL found in our previous study [16] were in the same chromosomal region as found by others $[14,19,23]$. The QTL regions are quite large $(50-100 \mathrm{cM})$ and only partially overlapping. Furthermore, different phenotypic measurements were used in the other studies $[14,19,23]$. Therefore, confirmation of the presence and location of the QTL is still needed, by performing a confirmation experiment.

Confirmation experiments have been described in several studies. In a backcrossing experiment in the pig, the presence of one or more QTL for fatness and growth was confirmed on pig chromosome 4 [18]. Furthermore, a grandgranddaughter design in dairy cattle has been used successfully to confirm QTL affecting milk yield [1,5]. Another example to confirm QTL is the use of an advanced intercross line (AIL). In mice, for example, this resulted in the confirmation of QTL found in an earlier study [15, 29,30]. Basically, an AIL is a population used for the fine-mapping of a QTL region and it is created by repeated intercrossing for a number of generations [7]. Because it is most suited for animals having a short generation interval, the AIL approach can be used in chickens.

The current report describes the use of an AIL to confirm the results of an earlier QTL mapping study. Therefore, from the previously used threegeneration population [16] a generation $9\left(\mathrm{G}_{9}\right)$ population was produced by random intercrossing in each generation from generation $2\left(\mathrm{G}_{2}\right)$ onwards. The results of the analysis of the $\mathrm{G}_{9}$ population are presented in the present study. 


\section{MATERIAL AND METHODS}

\subsection{Experimental population and observations}

The three-generation full sib half sib design described by Van Kaam et al. [26] was used in a previous study to detect QTL affecting fatness [16]. The $\mathrm{G}_{2}$ animals of this design were used to produce a $\mathrm{G}_{9}$ population by random intercrossing in each generation. The population structure and number of animals are given in Table I. In total, 12 full sib $\mathrm{G}_{8} / \mathrm{G}_{9}$ families were produced with on average 84 offspring. The $\mathrm{G}_{9}$ population consists of 546 male and 460 female animals.

The $\mathrm{G}_{9}$ animals were raised in 15 hatches and housed in a litter system for broilers. Animal density was around 20 animals $/ \mathrm{m}^{2}$. The animals were in the same pen starting from day 0 , where they received feed and water for $a d$ libitum consumption and illumination was $23 \mathrm{~h}$ a day. A commercial broiler feed containing $12970 \mathrm{~kJ} \cdot \mathrm{kg}^{-1}$ was used.

The birds were weighed at 5 weeks of age (BW5) and again at slaughter when they were 7 weeks of age (BW7). Around this age, commercial broilers reached the slaughter weight of $2 \mathrm{~kg}$. After slaughter, the weight of the abdominal fat pad (AFW) was measured and the percentage of abdominal fat (AF\%) was calculated. In addition, intramuscular fat content of part of the breast muscle, pectoralis minor was determined by means of extraction (Soxhlet method; NEN-ISO 1444 [9]) and the percentage of intramuscular fat (IF\%) was calculated.

\subsection{QTL regions}

In the previous QTL analysis, QTL for AFW and AF\% were found on chromosomes 1, 2, 3, 4, 7, 11, 13, 15, 18 and 27 [16]. From the results of this analysis six chromosomes were chosen for further analysis in the $\mathrm{G}_{9}$ population. Chromosomes 1, 4, 15, and 18 were selected because they showed significant evidence for QTL for both AFW and AF\%. All other chromosomes had a suggestive QTL for either AFW or AF\%, therefore only the most promising chromosomes (chromosomes 3 and 27) were selected.

\subsection{Genotyping}

Genotyping of the microsatellite markers was done as described previously [6]. PCR amplifications were carried out in $12 \mu \mathrm{L}$ reactions containing 10-60 ng genomic DNA, $1.5 \mathrm{mM} \mathrm{MgCl} 2,50 \mathrm{mM} \mathrm{KCl}, 10 \mathrm{mM}$ Tris- $\mathrm{HCl}$ 
Table I. Population structure and number of animals used for breeding, genotyping, and phenotyping.

\begin{tabular}{|c|c|c|c|}
\hline \multirow[t]{2}{*}{ Generation $^{1}$} & \multicolumn{3}{|c|}{ Number of animals } \\
\hline & Breeding & QTL & halysis \\
\hline $\mathrm{G}_{0}$ & 28 & & \\
\hline $\mathrm{G}_{1}$ & 20 & 20 & genotyped \\
\hline $\mathrm{G}_{2}$ & 71 & 456 & genotyped \\
\hline $\mathrm{G}_{3}$ & 105 & 5363 & phenotyped \\
\hline $\mathrm{G}_{4}$ & 122 & & \\
\hline $\mathrm{G}_{5}$ & 93 & & \\
\hline $\mathrm{G}_{6}$ & 108 & & \\
\hline $\mathrm{G}_{7}$ & 127 & & \\
\hline $\mathrm{G}_{8}$ & 100 & 24 & genotyped \\
\hline $\mathrm{G}_{9}$ & - & 1006 & genotyped \& phenotyped \\
\hline
\end{tabular}

${ }^{1} \mathrm{G}_{0}$, etc. $=$ Generation 0 , etc.

$(\mathrm{pH}=8.3), 1 \mathrm{mM}$ tetra-methylammoniumchloride (TMAC), $0.1 \%$ Triton $\mathrm{X}$ 100, $0.01 \%$ gelatin, $0.2 \mathrm{mM}$ each dNTP, $0.25 \mathrm{U}$ Silverstar polymerase (Eurogentec, Liege, Belgium) and 2.3 pmol of each primer, one of which was labeled with a fluorescent dye (FAM, TET and HEX) at the $5^{\prime}$ end. The amplification reactions were as follows: $5 \min 95^{\circ} \mathrm{C}$ followed by 35 cycles of $30 \mathrm{~s} 94{ }^{\circ} \mathrm{C}, 45 \mathrm{~s}$ at 50 or $55^{\circ} \mathrm{C}$ and $90 \mathrm{~s}$ at $72{ }^{\circ} \mathrm{C}$, followed by a final elongation step of $10 \mathrm{~min}$ at $72{ }^{\circ} \mathrm{C}$. Per animal PCR amplification products for 7 to 10 markers were combined and analyzed simultaneously on a $6 \%$ denaturing polyacrylamide gel, Sequagel-6 (National Diagnostics, Atlanta, GA, USA) on an ABI377 automatic sequencer (Applied Biosystems, Perkin Elmer, Foster City, CA, USA). Electrophoresis was performed for $2 \mathrm{~h}$ on $12 \mathrm{~cm}$ gels, and the results were analyzed using the Genescan and Genotyper software (Applied Biosystems, Perkin Elmer, Foster City, CA, USA).

A set of eight microsatellite markers was used to check the parentage from $\mathrm{G}_{2}$ to $\mathrm{G}_{9}$. For the QTL analysis, genotypes for $12 \mathrm{G}_{8} / \mathrm{G}_{9}$ full sib families (1030 animals) were determined with 22 microsatellite markers. These 22 markers were located on chromosomes $1,3,4,15,18$, and 27. The linkage map used in the present study was calculated with CRIMAP [11]. Further analyses were performed, using the recombination fractions obtained from CRIMAP [11] which were transformed to Haldane map distances [13] in the homemade QTL analysis program [26]. More information on the marker data is given in Table II. 
Table II. Chromosomes and microsatellite markers that were used for the full sib QTL analysis in $\mathrm{G}_{8} / \mathrm{G}_{9}$. Map distances are given in $\mathrm{cM}$ on the Haldane scale.

\begin{tabular}{|c|c|c|}
\hline Chromosome & Microsatellite markers & Map distance (cM) \\
\hline \multirow[t]{8}{*}{1} & $M C W 0044$ & 0 \\
\hline & MCW0289 & 8.7 \\
\hline & MCW0297 & 16.3 \\
\hline & $A D L 0364$ & 23.8 \\
\hline & ADL0359 & 44.6 \\
\hline & $M C W 0018$ & 73.6 \\
\hline & $M C W 0058$ & 114.6 \\
\hline & MCW0101 & 122.2 \\
\hline \multirow[t]{3}{*}{3} & $M C W 0116$ & 0 \\
\hline & $M C W 0148$ & 2 \\
\hline & $M C W 0037$ & 3.1 \\
\hline \multirow[t]{2}{*}{4} & LEIO122 & 0 \\
\hline & $M C W 0276$ & 63.6 \\
\hline \multirow[t]{3}{*}{15} & $M C W 0031$ & 0 \\
\hline & LEIOI20 & 6.4 \\
\hline & MCW0052 & 28.7 \\
\hline \multirow[t]{3}{*}{18} & MCW0045 & 0 \\
\hline & MCW0217 & 25.5 \\
\hline & ADL0290 & 36.7 \\
\hline \multirow[t]{4}{*}{27} & MCW0076 & 0 \\
\hline & MCW0328 & 11.2 \\
\hline & $A D L 0376$ & 23.6 \\
\hline & & Total: 277.9 \\
\hline
\end{tabular}

\subsection{QTL analysis}

Full sib QTL analysis was conducted using the regression interval mapping methodology as described by Van Kaam et al. [26] in which a single QTL was fitted. The analysis is an across family weighted full sib regression analysis. Because marker-QTL linkage phase can differ between families, QTL analysis was nested within families. Phenotypic values of $\mathrm{G}_{9}$ animals were regressed on the probabilities of inheriting the first allele of each $\mathrm{G}_{8}$ parent. Phenotypic 
values were adjusted for fixed effects sex (2 classes) and week of hatching (15 classes). In the model, the family mean was included in order to account for polygenic differences between families. The model to fit a QTL at position $k$ was:

$$
y_{i j}=f_{i}+b_{s, i k} x_{s, i j k}+b_{d, i k} x_{d, i j k}+e_{i j k}
$$

where: $y_{i j}=$ the average adjusted progeny trait value for $\mathrm{G}_{9}$ chicken $j$ of family $i ; f_{i}=$ the polygenic effect of family $i ; b_{s, i k}=$ the regression coefficient for the sire(s) of family $i$ at position $k ; x_{s, i j k}=$ the probability that the $\mathrm{G}_{9}$ chicken $j$ in family $i$ at position $k$ received the chromosomal segment from haplotype 1 from the sire; $b_{d, i k}=$ the regression coefficient for the dam (d) of family $i$ at position $k ; x_{d, i j k}=$ the probability that the $\mathrm{G}_{9}$ chicken $j$ in family $i$ at position $k$ received the chromosomal segment from haplotype 1 from the dam; $e_{i j k}=$ the random residual.

Test statistics were calculated at each centimorgan, in order to test for the presence of QTL effects $v s$. the absence of QTL effects. The test statistic was the ratio of the explained mean square of the QTL effects in the numerator and the residual mean square of the full model in the denominator.

\subsection{Significance thresholds}

Chromosome-wise significance thresholds were calculated using the method of permutation testing [4]. This is an empirical method, which accounts for the distribution of the marker and phenotypic data. For each trait, 10000 permutations at $1 \mathrm{cM}$ intervals for each chromosome were performed. Considering that six independent chromosomes were analysed and assuming the number of significant chromosomes to follow a binomial distribution, the required threshold on the chromosome level $P \mathrm{c}$ is such that $6 P \mathrm{c}=1$, i.e. $P c \sim 0.16$. For claiming significant linkage, we applied the 5\% experimentwise significance level. Experiment-wise significance levels, taking into account testing of all the chromosomes, were calculated as: $P g=1-(1-P \mathrm{c})^{1 / r}$, where $(r)$ was obtained by dividing the length of a specific chromosome by the total length of all chromosomes. This is computationally more efficient than performing experiment-wise permutations, because in the current approach permutations only have to be performed for chromosomes that show evidence for QTL. 


\section{RESULTS AND DISCUSSION}

\subsection{QTL analysis $\mathbf{G}_{8} / \mathbf{G}_{9}$}

From the results of the QTL analysis for AFW and AF\% in the previous study [16], chromosomes 1, 3, 4, 15, 18, and 27 were chosen for further analysis in the $\mathrm{G}_{9}$ population.

For the QTL analysis, three sets of a total 22 microsatellite markers were used on $12 \mathrm{G}_{8} / \mathrm{G}_{9}$ full sib families (1030 animals) resulting in over 22000 genotypes. These markers were only used to confirm the presence of the previously detected QTL in the AIL. Where possible, for each QTL region, three microsatellite markers were chosen, i.e. two at the border of the $95 \%$ confidence interval (CI) of the QTL and one in the middle. However, on chromosome 3 the three microsatellite markers were situated much closer together than the $95 \%$ CI and on chromosome 4 only two microsatellite markers were used. The QTL region on chromosome 1 was approximately four times as big as the other QTL regions, therefore more markers (eight) were chosen. For the selected chromosomal regions the marker order and map distance in $\mathrm{cM}$ on the Haldane scale [13] is shown in Table II. Marker order is the same as in the consensus linkage map reported by Groenen et al. [12] and map distances recalculated for $\mathrm{cM}$ on the Kosambi scale [17] are comparable to those in the consensus linkage map.

The results of the full sib QTL analysis are summarized in Table III. QTL were detected for at least one of the traits AFW, AF\%, BW5, BW7, and/or IF\% on chromosomes 1, 3, 15, and 27. For chromosomes 4 and 18, test statistics did not exceed the significance threshold for any of the traits measured in this experiment. On chromosome 1 two distinct QTL regions were identified (Fig. 1). In the region 0-30 cM, suggestive evidence was found for AFW and $\mathrm{AF} \%$ and in the region 40-120 cM, significant evidence was found for BW5 and BW7 and suggestive evidence for AFW, AF\%, and IF\%. Suggestive QTL were found on chromosome 15 for BW5 and on chromosome 27 for $\mathrm{AF} \%, \mathrm{BW}$, and IF\%. Furthermore, evidence on the chromosome-wise level was found on chromosome 3 for AFW, AF\%, and BW7.

\subsection{Power of the QTL analysis}

Power was calculated using the methods described by Van der Beek et al. [25], assuming a QTL heterozygosity of 0.5 and an average distance between informative markers of $20 \mathrm{cM}$. In the three-generation experiment, 
Table III. QTL for abdominal fat weight (AFW), percentage abdominal fat (AF\%), body weight at 5 (BW5) and 7 (BW7) weeks of age, and percentage intramuscular fat $(\mathrm{IF} \%)$ in the $\mathrm{G}_{8} / \mathrm{G}_{9}$ population of chickens derived from a broiler $\times$ broiler cross. Positions are given in $\mathrm{cM}$ on the Haldane scale.

\begin{tabular}{cccccc}
\hline Trait & Chromosome & Position $(\mathrm{cM})$ & Marker bracket & F-ratio & $P$-value \\
\hline AFW & 1 & 10 & $M C W 0289-M C W 0297$ & 1.559 & $0.23^{\dagger}$ \\
& & 82 & $M C W 0018-M C W 0058$ & 1.882 & $0.052^{\mathrm{c}, \dagger}$ \\
& 3 & 0 & $M C W 0116-M C W 0148$ & 1.430 & $0.062^{\mathrm{c}}$ \\
AF\% & 1 & 11 & $M C W 0289-M C W 0297$ & 1.474 & $0.29^{\dagger}$ \\
& & 84 & $M C W 0018-M C W 0058$ & 1.732 & $0.11^{\mathrm{c}, \dagger}$ \\
& 3 & 0 & $M C W 0116-M C W 0148$ & 1.364 & $0.086^{\mathrm{c}}$ \\
& 27 & 11 & $M C W 0076-A D L 0376$ & 1.848 & $0.016^{\mathrm{c}, \dagger}$ \\
BW5 & 1 & 68 & $A D L 0359-M C W 0018$ & 2.135 & $0.018^{\mathrm{c}, *}$ \\
& 15 & 19 & $L E I 0120-M C W 0052$ & 2.027 & $0.0093^{\mathrm{c}, \dagger}$ \\
& 27 & 9 & $M C W 0076-M C W 0376$ & 1.494 & $0.089^{\mathrm{c}, \dagger}$ \\
BW7 & 1 & 83 & $M C W 0018-M C W 0058$ & 2.282 & $0.0061^{\mathrm{c}, *}$ \\
& 3 & 0 & $M C W 0116-M C W 0148$ & 1.397 & $0.080^{\mathrm{c}}$ \\
IF\% & 1 & 114 & $M C W 0018-M C W 0101$ & 1.464 & $0.30^{\dagger}$ \\
& 27 & 23 & $M C W 0328-A D L 0376$ & 1.750 & $0.036^{\mathrm{c}, \dagger}$ \\
\hline
\end{tabular}

${ }^{1}$ Chromosome-wise $P$-value; ${ }^{\mathrm{c}}$ chromosome-wise linkage; * experiment-wise significant linkage; ${ }^{\dagger}$ experiment-wise suggestive linkage.

the power of the design to detect a QTL with an effect of $0.3 \sigma_{\mathrm{p}}$ is approximately 0.33 with $\alpha$ as 0.05 . Using the same parameters, the power in the two generation $\left(\mathrm{G}_{8} / \mathrm{G}_{9}\right)$ full sib design was 0.85 , showing that the design of the present study was very powerful and that true and false QTL should be distinguishable. Nevertheless, one may fail to confirm the QTL in a subsequent experiment for several reasons as indicated by Marklund et al. [18]. For example the original observation may be a type I error or a large QTL effect may be caused by several linked QTL each with a small effect, and the linkage may break up in subsequent generations.

In the present study we consider a suggestive QTL from the previous study to be confirmed when in the present study the test statistics exceed the significance threshold for chromosome-wise linkage or suggestive linkage. A comparison between the results of both studies is shown in Table IV. 


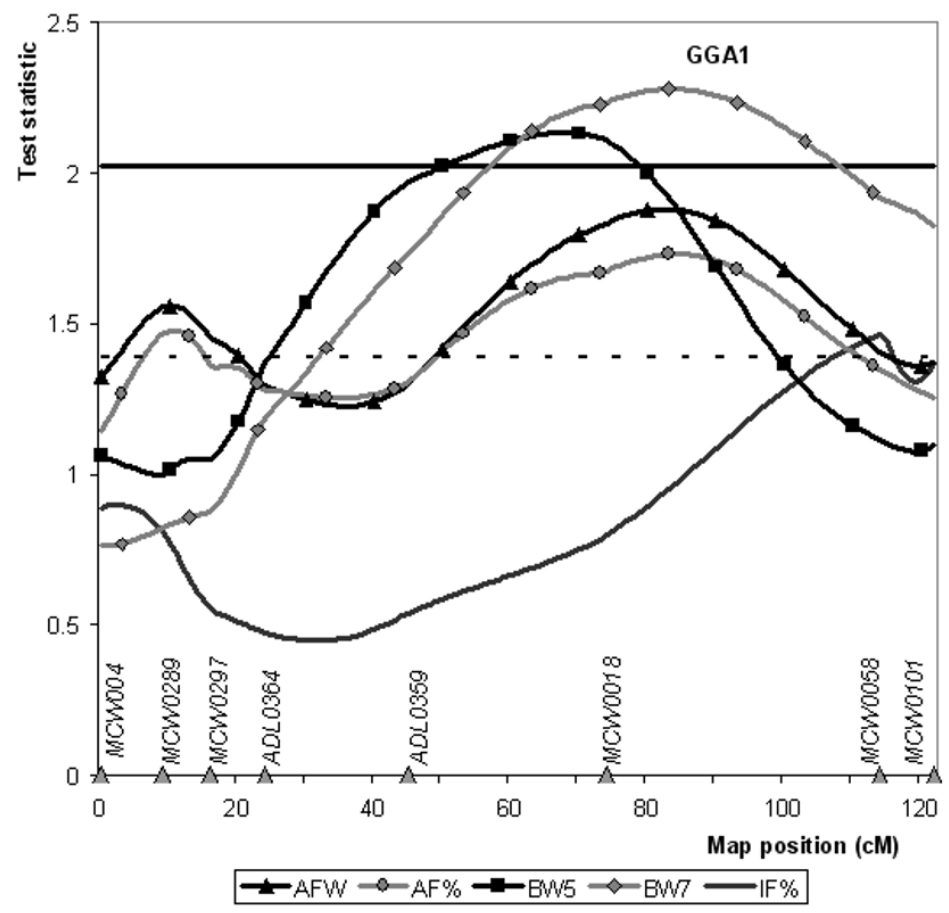

Figure 1. Test statistic values from the full sib QTL analysis for abdominal fat weight (AFW), percentage abdominal fat (AF\%), body weight at the age of 5 and 7 weeks (BW5 and BW7), and percentage intramuscular fat (IF\%) on chicken chromosome 1. Average thresholds for significance linkage at the 5\% level (- ${ }_{-}$) and for suggestive linkage (- - -) are included. Map positions are given in cM on the Haldane scale.

\subsection{QTL for abdominal fatness}

On chromosome 1 the QTL for AFW as well as AF\% were confirmed (Tab. IV). Moreover, for both traits the analysis revealed two distinct peaks on this chromosome at a distance of around $75 \mathrm{cM}$ (Fig. 1). An additional two QTL regression analyses were undertaken by fitting two QTL for both AFW and AF\%. Significance levels were obtained by two dimensional permutation to test for the presence of two QTL versus one QTL. The significance level was adjusted to the experiment-wise level using the same adjustment as applied in the single QTL analysis. The results of this analysis suggest that two distinct QTL for fat deposition are present on this chromosome $(P g<0.08$ for AFW and $P g<0.16$ for AF\%). The two QTL (the first between MCW0289MCW0297 and the second between MCW0018-MCW0058) are suggestive for both AFW and AF\%. Support for the QTL between MCW0289-MCW0297 is 
Table IV. Significance levels for QTL regions included in the $\mathrm{G}_{8} / \mathrm{G}_{9}$ population. Traits are abdominal fat weight (AFW) and percentage abdominal fat (AF\%) at 7 weeks of age, body weight at 5 (BW5) and 7 (BW7) weeks of age, and percentage intramuscular fat $(\mathrm{IF} \%)$ at 7 weeks of age.

\begin{tabular}{cccccccccccc}
\hline Chr & \multicolumn{2}{c}{$\mathrm{AFW}$} & \multicolumn{2}{c}{$\mathrm{AF} \%$} & \multicolumn{2}{c}{$\mathrm{BW}$} & \multicolumn{2}{c}{$\mathrm{BW} 7$} & \multicolumn{2}{c}{$\mathrm{IF} \%$} \\
& $\mathrm{G}_{2} / \mathrm{G}_{3}$ & $\mathrm{G}_{8} / \mathrm{G}_{9}$ & $\mathrm{G}_{2} / \mathrm{G}_{3}$ & $\mathrm{G}_{8} / \mathrm{G}_{9}$ & $\mathrm{G}_{2} / \mathrm{G}_{3}$ & $\mathrm{G}_{8} / \mathrm{G}_{9}$ & $\mathrm{G}_{2} / \mathrm{G}_{3}$ & $\mathrm{G}_{8} / \mathrm{G}_{9}$ & $\mathrm{G}_{2} / \mathrm{G}_{3}$ & $\mathrm{G}_{8} / \mathrm{G}_{9}$ \\
\hline 1 & $\dagger^{1}$ & $\mathrm{c}, \dagger$ & $* 1$ & $\mathrm{c}, \dagger$ & $\mathrm{nd}$ & $\mathrm{c},{ }^{*}$ & - & $\mathrm{c},{ }^{*}$ & $\mathrm{nd}$ & $\dagger$ \\
3 & - & $\mathrm{c}$ & $\dagger^{3}$ & $\mathrm{c}$ & $\mathrm{nd}$ & - & - & $\mathrm{c}$ & $\mathrm{nd}$ & - \\
4 & $\dagger^{2,3}$ & - & $\dagger^{2}$ & - & $\mathrm{nd}$ & - & - & - & $\mathrm{nd}$ & - \\
15 & $\dagger^{1}$ & - & $\dagger^{1,2,3}$ & - & $\mathrm{nd}$ & $\mathrm{c}, \dagger$ & - & - & $\mathrm{nd}$ & - \\
18 & $\dagger^{1}$ & - & $\dagger^{1}$ & - & $\mathrm{nd}$ & - & - & - & $\mathrm{nd}$ & - \\
27 & - & - & $\dagger^{2}$ & $\mathrm{c}, \dagger$ & $\mathrm{nd}$ & $\mathrm{c}, \dagger$ & - & - & nd & $\mathrm{c}, \dagger$ \\
\hline
\end{tabular}

c Chromosome-wise linkage; $*$ significant linkage; $\uparrow$ suggestive linkage; nd not determined.

${ }^{1}$ Effect detected at 10 weeks of age. ${ }^{2}$ Effect detected at 9 weeks of age. ${ }^{3}$ Effect detected at 7 weeks of age.

also given by Ikeobi et al. [14], who reported a QTL for abdominal fatness, which co-locates with ours. The 95\% CI (determined by bootstrapping) of the first and second QTL are 25 and $60 \mathrm{cM}$, respectively. This is considerably smaller than the $\mathrm{CI}$ of the $\mathrm{G}_{2} / \mathrm{G}_{3}$ QTL $(\sim 145 \mathrm{cM})$. The reduction of the $\mathrm{CI}$ is due to the increased number of informative meioses as a result of the larger number of animals used in the $\mathrm{G}_{9}$.

The suggestive QTL for AF\% on chromosomes 3 and 27 were also confirmed in this study and evidence at the chromosome-wise level for AFW was detected on chromosome 3. The QTL on chromosome 27 is supported by McElroy et al. [19] who found a suggestive linkage for fat weight $(P=0.06)$ with a single marker (MCW0233), close to our QTL. For the QTL region on chromosome 3, no other fatness QTL have been reported in the literature.

The suggestive QTL for AFW and AF\% previously found on chromosomes 4,15 , and 18 could not be confirmed, suggesting that the previously found QTL were falsely identified. However, power was calculated using a marker distance of $20 \mathrm{cM}$, while on chromosome 4 marker distance is $63.6 \mathrm{cM}$ (Tab. II). Therefore, power to detect a QTL on this chromosome with an effect of $0.3 \sigma_{\mathrm{p}}$ is approximately 0.52 with $\alpha$ is 0.05 . This is considerably lower than the previous calculated power of 0.85 , as is the chance to detect a QTL. Therefore, we cannot completely exclude the possibility of the presence of a QTL for abdominal fatness on chromosome 4. Furthermore, Ikeobi et al. [14] found significant QTL for fatness traits on chromosome 15 in the same region as the 
previous identified QTL in the $\mathrm{G}_{2} / \mathrm{G}_{3}$ population [16]. These results suggest that there might be genes located on this chromosome, which are involved in the regulation of fat deposition.

\subsection{QTL for body weight}

Evidence for QTL for BW5 and/or BW7 was found on chromosomes 1, 3, 15, and 27 (Tab. III). In the three-generation design of our previous study [16] we did not find any evidence for the presence of QTL with an effect on BW on these chromosomes. However, in our group, several QTL studies were performed using the same three generation design, with the same genetic background, but different $\mathrm{G}_{3}$ offspring [26-28]. In two of these studies, a suggestive QTL for BW7 was identified on chromosome 1 near microsatellite markers MCW0058 and LEI0071 [26, 27], which is confirmed by the results of the present study.

The presence of QTL for BW on chromosomes 1, 15 and 27 is supported by the results of several other QTL studies. In the same region on chromosome 1 Tatsuda and Fujinaka [24] detected QTL for BW at 13 and 16 weeks of age. Furthermore, Carlborg et al. [3] found QTL on chromosomes 15 and 27, whereas, Sewalem et al. [21] did on chromosomes 1 and 27.

\subsection{QTL for intramuscular fat}

In addition to the traits $\mathrm{AFW}, \mathrm{AF} \%$ and $\mathrm{BW}$, which have been analyzed in several QTL studies, IF\% was also analyzed in this study. So far no QTL mapping studies have been conducted for this trait in poultry. We found suggestive evidence for IF\% on chromosomes 1 and 27. Considering the fact that on chromosomes 1 and 27 evidence was also found for BW, AFW and/or AF\% (Tab. III; Fig. 1), it is likely that the underlying gene has pleiotropic effects. The estimation of genetic parameters on the present data [31] showed that IF\% and BW were genetically highly correlated $(0.87-0.91)$, whereas the genetic correlation between $\mathrm{AF} \%$ and $\mathrm{IF} \%$ was negative (-0.31) and between AFW and IF\% it was almost zero (0.02). These correlations suggest [10] that the metabolic pathways for growth and fat deposition in the muscles are influenced by the same genes in the same direction, whereas the metabolic pathway for fat deposition in the abdomen might be influenced by these genes in the opposite directions or even by other genes. 


\section{CONCLUSION}

The results of this study show the confirmation of QTL found in an earlier generation in an AIL. Moreover, on chromosome 1 we were able to identify two distinct regions for fat deposition. This is the first step towards the fine mapping of the QTL for fat deposition. Nevertheless, the identification of conserved chromosomal segments (i.e. haplotype blocks), which are associated with the observed QTL will be needed to further reduce the size of the QTL regions. To identify these haplotype blocks more densely spaced markers are needed. Therefore, new markers (i.e. SNPs) need to be developed. This is an essential step before moving towards the next phase of identifying the underlying genes responsible for the observed QTL.

\section{ACKNOWLEDGEMENTS}

We thank Piet de Groot, Anita Grootemaat, Bram Kamps, Tineke Veenendaal, and Henk Vos for their effort in collecting the phenotypic and genotypic data. We acknowledge Nutreco, Breeding Research Center for their collaboration and financial support. This work was financially supported by the Netherlands Technology Foundation (STW; grant WBI.4706).

\section{REFERENCES}

[1] Arranz J.-J., Coppieters W., Berzi P., Cambisano N., Grisart B., Karim L., Marcp F., Moreau L., Mezer C., Riquet J., Simon P., Vanmanshoven P., Wagenaar D., Georges M., A QTL affecting milk yield and composition maps to bovine chromosome 20: a confirmation, Anim. Genet. 29 (1998) 107-115.

[2] Bennewitz J., Reinsch N., Grohs C., Leveziel H., Malafosse A., Thomsen H., Xu N., Looft C., Kuhn C., Brockmann G.A., Schwerin M., Weimann C., Hiendleder S., Erhardt G., Medjugorac I., Russ I., Forster M., Brenig B., Reinhardt F., Reents R., Averdunk G., Blumel J., Boichard D., Kalm E., Combined analysis of data from two granddaughter designs: A simple strategy for QTL confirmation and increasing experimental power in dairy cattle, Genet. Sel. Evol. 35 (2003) 319-338.

[3] Carlborg Ö., Kerje S., Schütz K., Jacobsson L., Jensen P., Andersson L., A global search reveals epistatic interaction between QTL for early growth in the chicken, Genome Res. 13 (2003) 413-421.

[4] Churchill G.A., Doerge R.W., Empirical threshold values for quantitative trait mapping, Genetics 138 (1994) 963-971.

[5] Coppieters W., Riquet J., Arranz J.J., Berzi P., Cambisano N., Grisart B., Karim L., Marcq F., Moreau L., Nezer C., Simon P., Vanmanshoven P., Wagenaar D., 
Georges M., A QTL with major effect on milk yield and composition maps to bovine chromosome 14, Mamm Genome. 9 (1998) 540-544.

[6] Crooijmans R.P.M.A., Dijkhof R.J.M., Van der Poel J.J., Groenen M.A.M., New microsatellite markers in chicken optimized for automated fluorescent genotyping, Anim. Genet. 28 (1997) 427-437.

[7] Darvarsi A., Soller M., Advanced intercross lines, an experimental population for fine genetic mapping, Genetics 141 (1995) 1199-1207.

[8] De Koning D.J., Windsor D., Hocking P.M., Burt D.W., Law A., Haley C.S., Morris A., Vincent J., Griffin H.J., Quantitative trait locus detection in commercial broiler lines using candidate regions, J. Anim. Sci. 81 (2003) 1158-1165.

[9] Dutch Center for Standardization NEN. http://www.nen.nl. [Consulted: March 2003].

[10] Falconer D.S., Mackay T.F.C., Introduction to quantitative genetics, 4th edn., Essex, 1996.

[11] Green P., Falls K., Crooks S., Documentation for Cri-MAP Version 2.4, Washington University School of Medicine, St. Louis, MO, USA, 1990.

[12] Groenen M.A.M., Cheng H.H., Bumstead N., Benkel B.F., Briles W.E., Burke T., Burt D.W., Critteden L.B., Dodgson J., Hillel J., Lamont S., Ponce de Leon F.A., Soller M., Takahashi H., Vignal A., A consensus linkage map of the chicken genome, Genome Res. 10 (2000) 137-147.

[13] Haldane J.B.S., The combination of linkage values and the calculation of distances between the loci of linked factors, J. Genet. 2 (1919) 3-19.

[14] Ikeobi C.O.N., Woolliams J.A., Morrice D.R., Law A., Windsor D., Burt D.W., Hocking P.M., Quantitative trait loci affecting fatness in the chicken, Anim. Genet. 33 (2002) 428-435.

[15] Iraqi F., Clapcott S.J., Kumari P., Haley C.S., Kemp S.J., Teale A.J., Fine mapping of trypanosomiasis resistance loci in murine advanced intercross lines, Mamm. Genome 11 (2000) 645-648.

[16] Jennen D.G.J., Vereijken A.L.J., Bovenhuis H., Crooijmans R.P.M.A., Veenendaal A., Van der Poel J.J., Groenen M.A.M., Detection and localization of quantitative trait loci affecting fatness in broilers, Poult. Sci. 83 (2004) 295-301.

[17] Kosambi D.D., The estimation of map distances from recombination values, Ann. Eugen. 12 (1944) 172-175.

[18] Marklund L., Nyström P.-E., Stern S., Andersson-Eklund L., Andersson L., Confirmed quantitative trait loci for fatness and growth on pig chromosome 4, Heredity 82 (1999) 134-141.

[19] McElroy J.P., Harry D.E., Dekkers J.C.M., Lamont S.J., Molecular markers associated with growth and carcass traits in meat-type chickens, in: Proc. 7th World Cong. Genet. Appl. Livest. Prod., 19-23 August 2002, Vol. 30, Montpellier, France, pp. 209-212.

[20] Pitel F., Lagarrigue S., Le Roy P., Plisson-Petit F., Amigues Y., Neau A., Cahaner A., Hillel J., Sourdioux M., Leclerq B., Vignal A., Douaire M., A two-step procedure for fat QTL identification in meat-type chickens, in: Proc. 7th World Cong. Genet. Appl. Livest. Prod., 19-23 August 2002, Vol. 30, Montpellier, France, pp. 345-348. 
[21] Sewalem A., Morrice D.M., Law A., Windsor D., Haley C.S., Ikeobi C.O.N., Burt D.W., Hocking P.M., Mapping of quantitative trait loci for body weight at three, six and nine weeks of age in broiler layer cross, Poult. Sci. 81 (2002) 1775-1781.

[22] Siwek M., Buitenhuis A.J., Cornelissen S.J.B., Nieuwland M.G.B., Bovenhuis H., Crooijmans R.P.M.A., Groenen M.A.M., De Vries-Reilingh G., Parmentier H.K., Van der Poel J.J., Detection of different QTL for antibody responses to Keyhole Lympet Hemocyanin and Mycobacterium butyricum in two unrelated populations of laying hens, Poult. Sci. 82 (2003) 1845-1952.

[23] Tatsuda K., Fujinaka K., Genetic mapping of the QTL affecting abdominal fat deposition in chickens, J. Poult. Sci. 38 (2001) 266-274.

[24] Tatsuda K., Fujinaka K., Genetic mapping of the QTL affecting body weight in chickens using a F2 family, Br. Poult. Sci. 42 (2001) 333-337.

[25] Van der Beek S., van Arendonk J.A.M., Groen A.F., Power of two- and threegeneration QTL mapping experiments in an outbred population containing fullsib or half-sib families, Theor. Appl. Genet. 91 (1995) 1115-1124.

[26] Van Kaam J.B.C.H.M., van Arendonk J.A.M., Groenen M.A.M., Bovenhuis H., Vereijken A.L.J., Crooijmans R.P.M.A., Van der Poel J.J., Veenendaal A., Whole genome scan for quantitative trait loci affecting body weight in chickens using a three generation design, Livest. Prod. Sci. 54 (1998) 133-150.

[27] Van Kaam J.B.C.H.M., Groenen M.A.M., Bovenhuis H., Veenendaal A., Vereijken A.L.J., van Arendonk J.A.M., Whole genome scan in chickens for quantitative trait loci affecting growth and feed efficiency, Poult. Sci. 78 (1999) $15-23$.

[28] Van Kaam J.B.C.H.M., Groenen M.A.M., Bovenhuis H., Veenendaal A., Vereijken A.L.J., van Arendonk J.A.M., Whole genome scan in chickens for quantitative trait loci affecting carcass traits, Poult. Sci. 78 (1999) 1091-1099.

[29] Wang M., Lemon W.J., Liu G., Wang Y., Iraqi F.A., Malkinson A.M., You M., Fine mapping and identification of candidate pulmonary adenoma susceptibility 1 genes using advanced intercross lines, Cancer Res. 63 (2003) 3317-3324.

[30] Wang X., Le Roy I., Nicodeme E., Li R., Wagner R., Petros C., Churchill G.A., Harris S., Darvasi A., Kirilovsky J., Roubertoux P.L., Paigen B., Using advanced intercross lines for high-resolution mapping of HDL cholesterol quantitative trait loci, Genome Res. 13 (2003) 1654-1664.

[31] Zerehdaran S., Vereijken A.L.J., van Arendonk J.A.M., Van der Waaij E.H., Estimation of genetic parameters for fat deposition and carcass traits in broilers, Poult. Sci. 83 (2004) 521-525. 